\title{
Bilirubin Metabolism in Congenital Nonhemolytic Jaundice
}

\author{
Joseph R. Bloomer ${ }^{[34]}$, Paul D. Berk, Robert B. Howe, and Nathaniel I. Berlin \\ National Cancer Institute, National Institutes of Health, Bethesda, Maryland, USA
}

\begin{abstract}
Extract
A Negro female with congenital nonhemolytic jaundice (Crigler-Najjar syndrome) was studied over a period of 15 months. During this period the plasma bilirubin concentration averaged $20.6 \mathrm{mg} / 100 \mathrm{ml}$. Administration of phenobarbital did not lower the bilirubin concentration. Studies with isotopically labeled bilirubin showed that phenobarbital had not increased the fractional rate of elimination of bilirubin, and the patient's bilirubin production rate while receiving phenobarbital therapy $(3.5$ $\mathrm{mg} / \mathrm{kg} / 24 \mathrm{hr}$ ) was not increased over that seen in normal individuals $(3.8 \pm 0.6$ $\mathrm{mg} / \mathrm{kg} / 24 \mathrm{hr}$, mean $\pm \mathrm{sD}$ ).

Multicompartmental analysis of the patient's labeled bilirubin clearance data, as well as that from two other reported cases of congenital nonhemolytic jaundice, did not furnish new information on pathways of bilirubin catabolism but did demonstrate that the fractional transfer rate of bilirubin from plasma to liver for all three subjects $\left(0.42-0.87 \mathrm{hr}^{-1}\right)$ was reduced compared with the range seen in normal individuals $\left(0.9-2.0 \mathrm{hr}^{-1}\right)$. This finding may reflect saturation of either the hepatic uptake process or intracellular binding sites, in the face of a serum bilirubin concentration 20-40 times normal.

Menthol conjugation in the patient's parents was normal, unlike reported findings in parents of children with congenital nonhemolytic jaundice unresponsive to phenobarbital therapy. Labeled bilirubin clearances in the parents demonstrated an abnormality in the mother's pattern of clearance, whereas the father's clearance was normal.

The patient was found to excrete normal amounts of testosterone conjugated with glucuronic acid, demonstrating that the defect in glucuronide conjugation does not include all physiological compounds.
\end{abstract}

\section{Speculation}

Plasma clearance studies with labeled bilirubin can aid in the investigation of modes of inheritance of unconjugated hyperbilirubinemia.

\section{Introduction}

In 1952 Crigler and Najjar described the syndrome of congenital nonhemolytic jaundice (CNJ) [15]. The condition was characterized by the onset in the neona- tal period of a marked and persistent elevation of the serum concentration of indirectly reacting bilirubin (unconjugated bilirubin), in the absence of hemolysis. There have been fewer than 50 documented cases [24] 
Jaundice in this disease results from a deficiency of hepatic bilirubin glucuronyl transferase [2]. In addition, the metabolism of several other substrates normally excreted as the glucuronide is also impaired [24].

Recently Arias et al. [1] have shown that phenotypically similar patients with CNJ could be separated into two groups which differ in the apparent mode of inheritance, presence or absence of conjugated bilirubin in the bile, and response of the bilirubin concentration in serum to phenobarbital administration.

This paper describes studies of bilirubin metabolism and glucuronide conjugation in a Negro female with CNJ unresponsive to phenobarbital therapy. Plasma clearance studies with labeled bilirubin were also performed in the patient's parents. Such studies are of value in ascertaining the mode of inheritance of this syndrome, as well as other inherited abnormalities of bilirubin metabolism.

\section{Gase History}

$K D$ was the $7 \mathrm{lb}, 9 \mathrm{oz}$ product of term pregnancy in a 19 year-old Negro primigravida. The pregnancy was complicated by nausea and vomiting during the last trimester, treated with an unknown medication, and an episode of fever and cough during month 8 . Labor and delivery were uncomplicated. The child was discharged at the usual time without recognition of jaundice. The mother stated, however, that the child's eyes were yellow following birth and became progressively darker thereafter. The child was not breast fed.

At 26 days of age she was admitted to the University of Maryland Hospital for evaluation of jaundice. Physical examination was unremarkable except for jaundice. The indirectly reacting bilirubin level in serum was $28.5-36 \mathrm{mg} /$ $100 \mathrm{ml}$, with a directly reacting fraction of $0.1-1.0 \mathrm{mg} / 100$ $\mathrm{ml}$. Remaining liver function tests were normal, as was hematologic evaluation. An exploratory laparotomy demonstrated normal liver and spleen. Operative cholangiogram showed a normal duct system and gallbladder. Bile was not aspirated from the gallbladder. A liver biopsy revealed normal hepatic architecture by light microscopy. The patient was discharged on a regimen providing $60 \mathrm{mg}$ phenobarbital daily, and according to the mother had some decrease in scleral icterus, although there were no documented measurements of serum bilirubin. At home she developed normally, rolling over at 2 months, sitting without support at 6 months, and attempting to feed herself at 8 months. At 8.5 months she developed a fever and upper respiratory infection. During the course of the illness she developed grand mal seizure activity, which persisted for $24 \mathrm{hr}$ until controlled with diazepam [30] and phenobarbital. A lumbar puncture was negative. Following this episode the patient showed no further development, and in fact regressed. She no longer responded to her environment except to startle at loud noises, and she had recurrent grand mal and focal seizure activity. The dose of phenobarbital was gradually decreased prior to the patient's admission to the National Institutes of Health without significant increase in her seizure activity. She was admitted to the National Institutes of Health in March, 1968, at age 25 months.

Physical examination on admission revealed a deeply jaundiced Negro girl who was well below the 10th percentile in height and weight for her age. There were disconjugate eye movements with horizontal nystagmus. Optic atrophy was present bilaterally. The teeth were ground to the gum line. Examination of the heart, lungs, and abdomen was normal. The patient did not respond to the environment other than to blink at loud noises and withdraw from painful stimuli. All four extremities were held in flexion contraction with clasp knife spasticity. There was diffuse hyperreflexia with bilateral Babinski reflexes. The thumbs were held inside the tightly clenched fists.

An extensive family history failed to reveal a history of persistent jaundice in other members of the family, although a distant cousin was said to have had transient jaundice. No history of consanguinity between the parents was found in a study of six generations, although several instances were documented in close relatives. The patient had a 1-year-old sister who was in good health.

Laboratory data showed a hemoglobin concentration of $12.4 \mathrm{~g} / 100 \mathrm{ml}$, hematocrit $40.0 \%$, and reticulocyte count $1.1 \%$. The total bilirubin was $24.0 \mathrm{mg} / 100 \mathrm{ml}$ with 0.34 $\mathrm{mg} / 100 \mathrm{ml}$ direct, the alkaline phosphatase $17 \mathrm{KA}$ units, the serum glutamic oxaloacetic transaminase (SGOT) 20, and protein electrophoresis normal. The ${ }^{51} \mathrm{Cr}$ red cell $\mathbf{T}_{1 / 2}$ was 29.1 days. The Coomb's test was negative, and hemoglobin electrophoresis was normal. Duodenal aspiration on two occasions after fluoroscopic placement of the tube revealed alkaline duodenal contents with no measurable bilirubin. Bone marrow aspiration showed normocellular particles with an $M: E$ ratio of $3: 1$. A cineradiography study of the pharynx, performed because of repeated episodes of regurgitation during feeding, showed that the infant was capable of adequate voluntary swallow, but that a bolus in the pharynx frequently failed to evoke swallowing or apposition between tongue and soft palate. An electroencephalogram was diffusely abnormal, but a brain scan and lumbar puncture were both normal. There was no measurable bilirubin in the spinal fluid, despite a concentration in the serum in excess of $20 \mathrm{mg} / 100 \mathrm{ml}$.

Ten days after admission to the NIH diphenylhydantoin [31] was begun because of increasing grand mal seizure activity (Fig. 1). Approximately 1 month later the patient vomited after feeding, aspirated, and had a respiratory arrest. Nasotracheal suction removed large quantities of aspirated food and was followed by return of normal spontaneous respirations. No new neurological abnormalities were noted following the respiratory arrest. Sixteen days after the 


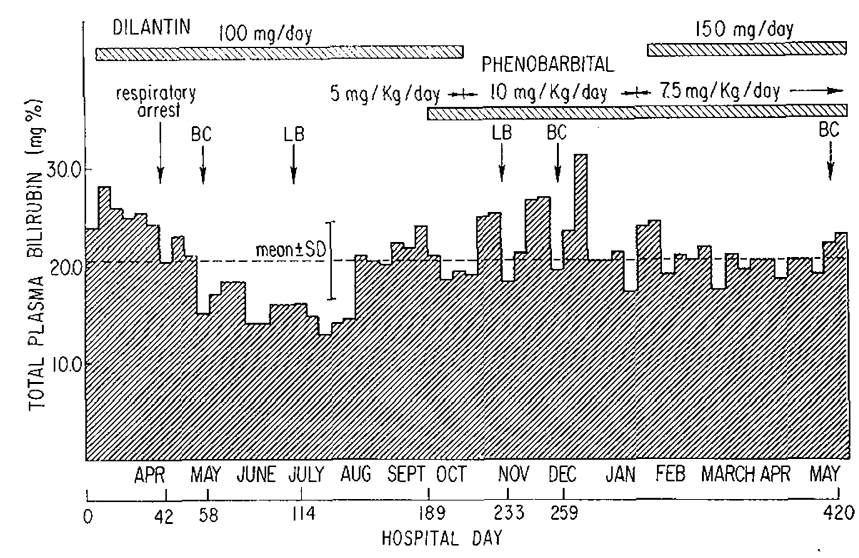

Fig. 1. The average weekly concentration of plasma bilirubin during the hospital course is shown, as well as the medications received. The procedures performed on the patient are illustrated by arrows, and the hospital days on which these procedures were done are listed below the figure. $\mathrm{BC}$ : isotopic bilirubin clearance. LB: liver biopsy.

arrest, when her condition had been stable for more than 10 days, the first labeled bilirubin clearance study was performed. Review of her chart indicated that blood samples drawn for diagnostic studies over 16 days following the arrest and during the initial part of the bilirubin clearance study amounted to approximately $20 \%$ of her total blood volume. None of this blood loss was replaced by transfusion.

\section{Methods}

\section{Preparation of Isotopic Bilirubin}

Bilirubin-14 $\mathrm{C}$ was prepared in bile fistula dogs from $\Delta$-aminolevulinic acid (ALA) $-{ }^{14} \mathrm{C}$ and purified to constant specific activity and a molar extinction coefficient of 58,000-61,000 [4]. Bilirubin- ${ }^{3} \mathrm{H}$ was prepared from ALA-2, $3-{ }^{3} \mathrm{H}$, by the same method [20]. In vivo studies have shown that this product behaves identically to bilirubin- ${ }^{14} \mathrm{C}[20]$.

\section{Isotopically Labeled Bilirubin Clearance Studies}

Labeled bilirubin clearances were carried out in the patient and her parents using methods previously described $[3,6]$. The patient received from 1.2 to $9.5 \mu \mathrm{Ci}$ in $1.8-2.1 \mathrm{mg}$ bilirubin $-{ }^{14} \mathrm{C}$ on the three occasions when she was studied. For their studies the father and mother each received $0.4 \mu \mathrm{Ci}$ in $0.7 \mathrm{mg}$ bilirubin $-{ }^{14} \mathrm{C}$. The mother received $35 \mu \mathrm{Ci}$ in $0.26 \mathrm{mg}$ bilirubin ${ }^{3} \mathrm{H}$ for her second study.

During study 1 multiple blood samples were obtained from the patient during the $48 \mathrm{hr}$ following injection of the labeled bilirubin, and then three times per week for 3 months. In studies 2 and 3 sufficient blood samples were obtained to define only the terminal exponential of the plasma bilirubin- ${ }^{14} \mathrm{C}$ disappearance curve. The early portions of the curves were not examined in detail. All plasma bilirubin concentrations were measured by the method of Weber and Schalm [28].

\section{Analysis of Bilirubin-14C Clearance Data}

The data were processed on a digital computer [32], with the use of the SAAM program of Berman and Weiss $[9,10]$. Three exponentials were both necessary and sufficient to describe the plasma clearance data for study $l$ in the patient and for the studies in her parents. Using the plasma curve integral method of analysis [22], the following parameters were calculated as previously described $[3,6]:(l) k_{e}$, the fractional turnover of the plasma unconjugated bilirubin pool per minute; (2) $\mathrm{C}_{\mathbf{B r}}$, the volume of plasma cleared of bilirubin each minute; (3) percentage retention of isotopically labeled bilirubin in the plasma at $4 \mathrm{hr}$.

In an attempt to gain additional insight into the metabolism of bilirubin in this condition, data from the patient's first bilirubin- ${ }^{14} \mathrm{C}$ clearance study, as well as the previously published studies of Schmid and Hammaker [25] and Crigler and Gold [14], were examined by the technique of multicompartmental analysis. The finding of three exponential components to the plasma bilirubin ${ }^{-14} \mathrm{C}$ disappearance curve suggests that there are two kinetically distinct unconjugated bilirubin pools which exchange reversibly with plasma [7, 8]. Analysis of similar data in normal subjects [6] and in patients with Gilbert's syndrome [5] has led to the hypothesis that these pools are an extrahepatic extravascular pool and an intrahepatic pool of unconjugated bilirubin, and that the exchanging pools are arranged in series. Accordingly, the patient's data were fit to several variations of the previously described pool arrangement [6], two examples of which are illustrated in Figure II. In model 1, all elimination of bilirubin from the exchanging pool system was assumed to occur directly from the liver, as indicated by pathway $\lambda_{\mathrm{F}, 2}$. In model 2 , elimination occurs directly from the plasma, as well as from the liver, in a ratio of 4:5. The latter ratio was selected on the basis of studies of the pathways of bilirubin elimination in the Gunn rat, an animal analogue of CNJ [25]. The hepatic bilirubin uptake was calculated from the plasma pool size and transfer rate from the plasma pool to the hepatic pool. It must be emphasized that the models 
are merely mathematical conceptualizations of the sites and rates of bilirubin elimination. They provide no information about the biochemical mechanisms involved. The mathematical techniques involved in compartmental analysis of bilirubin clearance data have been described previously in detail, along with an explicit statement of the assumptions involved and the limitations of the method [6].

\section{Menthol Tolerance Test}

Menthol was prepared as a $10 \%$ solution in sesame oil. On day 1, a 5-hr control urine was collected from 7 AM until noon. On the following day at 7 AM a measured amount of menthol ( $15 \mathrm{mg} / \mathrm{kg}$ body $\mathrm{wt}$ ) was given by mouth, and urine was collected for the subsequent $5 \mathrm{hr}$. In the case of the patient, the menthol was given through a nasogastric tube. Both urines were analyzed for glucuronide glucuronic acid according to the method of Fishman and Green [18]. The difference in glucuronide glucuronic acid output in the urines before and after menthol administration was compared with the amount of menthol given.

\section{Testosterone Conjugation Study}

The patient was given $3 \mu \mathrm{Ci}$ testosterone-7- $\alpha^{3} \mathrm{H}$ intravenously, and the urine was collected for 8 days. Urinary "glucuronides" were hydrolyzed with $\beta$-glucuronidase, and the liberated steroids were extracted with ether [21]. Urinary "sulfates" were hydrolyzed by solvolysis and extracted [21]. Both extracts were counted, and then testosterone was isolated by thin layer chromatography and derivative formation [21]. Testosterone-14 $\mathrm{C}$ was used to correct for procedural losses.

Fully informed consent was obtained for all studies in accordance with provisions set forth in the Declaration of Helsinki.

\section{Results}

The bilirubin concentration in plasma was measured two to three times per week over the course of a year. The average weekly concentrations, as well as the medications received, are shown in Figure 1. Less than 5\% of the bilirubin in any given sample was extracted into the polar phase (conjugated bilirubin) of the WeberSchalm separation system. Since studies in this laboratory indicate the efficiency of this system to be only 90 $95 \%$, this indicates a virtual absence of conjugated bilirubin in the patient's plasma.

The patient's plasma bilirubin concentration aver-

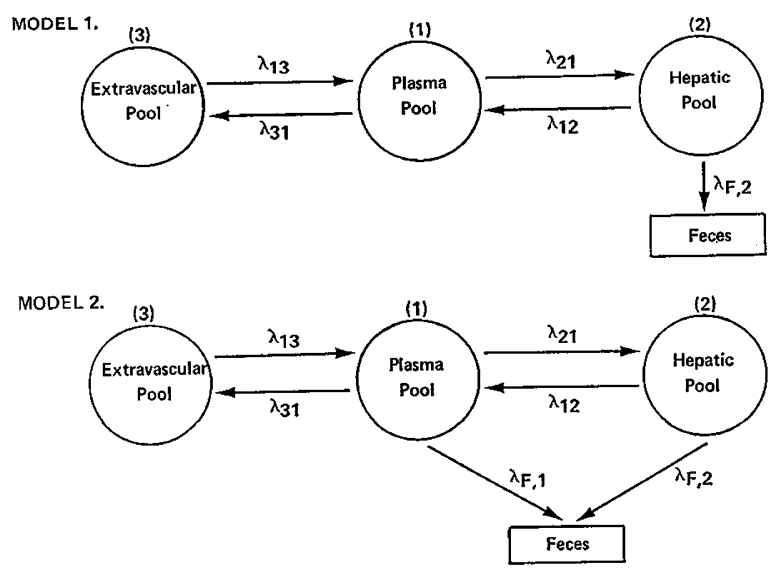

Fig. 2. Two examples of three-compartment models for the metabolism of unconjugated bilirubin which were used to fit the patient's bilirubin ${ }^{14} \mathrm{C}$ clearance data. Values for the $\lambda \mathrm{s}$, which are the fractional transfer rates between compartments, and for the ratio of pool sizes are calculated from the plasma disappearance curve of bilirubin ${ }^{14} \mathrm{C}$. In model 1 all elimination of bilirubin occurs from the liver (pathway $\lambda_{F, 2}$ ). In model 2 elimination occurs both from the plasma (pathway $\lambda_{F, 1}$ ) and from the liver (pathway $\lambda_{F, 2}$ ).

aged $24.0 \mathrm{mg} / 100 \mathrm{ml}$ during week 1 of hospitalization, when she was receiving no medication. The average during the entire period of hospitalization was 20.6 $\mathrm{mg} / 100 \mathrm{ml}$ (Fig. 1). The bilirubin concentration in plasma rose during periods of infection or gastrointestinal upset and was significantly lower during only one period of observation. This occurred during the spring and summer months, although the patient was not exposed to sunlight. At that time she was on diphenylhydantoin [31] for seizure control. Diphenylhydantoin will induce hepatic microsomal enzymes [13] and could in theory increase the rate of bilirubin catabolism, but as the bilirubin concentration subsequently rose on continuation of diphenylhydantoin therapy, this was an unlikely explanation. More likely the period of lower bilirubin concentration was a consequence of the blood sampling associated with the respiratory arrest. Since senescent erythrocytes are the principal source of bilirubin, a $20 \%$ reduction in the erythocyte mass would be expected to result in a corresponding decrease in bilirubin production, and hence in the unconjugated bilirubin concentration in plasma. Such a decrease in the bilirubin production rate was, in fact, documented by the labeled bilirubin clearance studies (Table I). Further support for this explanation is given by the fact that the bilirubin concentration rose again approximately 120 days later, the normal life span of the erythrocyte. These data are 
analogous to the experiments of Hawkins and Whipple [19], who deduced the life span of the erythrocyte from changes in bilirubin excretion in the bile fistula dog following phlebotomy.

Phenobarbital did not lower the bilirubin concentration in plasma. A barbiturate level of $5.8 \mathrm{mg} / 100$ $\mathrm{ml}$ in serum assured that this was not due to failure of absorption.

Variables of bilirubin metabolism calculated from the terminal slopes $[25,26]$ of the three clearance studies in the patient are listed in Table I. There was no difference between the slope of the terminal exponential while the patient was given diphenylhydantoin (study 1 ), as compared with that when she was given phenobarbital (study 2). In contrast, bilirubin production during study 1 was only $80 \%$ of that in study 2 , proportional to the reduction in circulating erythrocyte volume. Bilirubin production rate while the patient was given phenobarbital $(3.5 \mathrm{mg} / \mathrm{kg} / 24 \mathrm{hr}$ ) was normal compared with the value of $3.8 \pm 0.6 \mathrm{mg} / \mathrm{kg} /$ $24 \mathrm{hr}$ (mean $\pm \mathrm{SD}$ ) found by Berk et al. [6] in young healthy adults (see Table II). The value of $3.5 \mathrm{mg} / \mathrm{kg} /$ $24 \mathrm{hr}$ falls in between the bilirubin production rates of $3.0 \mathrm{mg} / \mathrm{kg} / 24 \mathrm{hr}$ [25] and $4.1 \mathrm{mg} / \mathrm{kg} / 24 \mathrm{hr}$ [14] measured previously in children with congenital nonhemolytic jaundice. Crigler and Gold [14] also found no

Table 1 . Terminal slope calculations on patient's isotopic bilirubin clearance studies

\begin{tabular}{|c|c|c|c|c|c|c|}
\hline Study & $\begin{array}{l}\text { Weight, } \\
\mathrm{kg}\end{array}$ & $\begin{array}{l}\text { Bilirubin conc, } \\
\mathrm{mg} / 100 \mathrm{ml}\end{array}$ & $\begin{array}{c}\text { Slope of } \\
\text { terminal } \\
\text { exponential, } \\
h \mathrm{hr}^{-1}\end{array}$ & $\underset{\mathrm{hr}}{\mathrm{T}_{1 / 2},}$ & $\begin{array}{l}\text { Total } \\
\text { bilirubin } \\
\text { pool, } \\
\text { mg/kg }\end{array}$ & $\begin{array}{l}\text { Bilirubin } \\
\text { turn- } \\
\text { over, } \\
\mathrm{mg} / \mathrm{kg} / \\
24 \mathrm{hr}\end{array}$ \\
\hline 1 & 7.50 & $\begin{array}{r}16.95 \\
\pm 0.30^{\mathrm{I}}\end{array}$ & 0.0042 & 165 & 26.9 & 2.7 \\
\hline 2 & 8.93 & $\begin{array}{r}23.27 \\
\pm 1.27\end{array}$ & 0.0043 & 161 & 34.2 & 3.5 \\
\hline 3 & 9.70 & $\begin{array}{r}22.60 \\
\pm \quad 1.69\end{array}$ & 0.0031 & 224 & 43.8 & 3.3 \\
\hline
\end{tabular}

1 Mean \pm SEM. increase in the bilirubin production rate when phenobarbital was administered to their patient.

Liver biopsies were obtained during diphenylhydantoin [31] and phenobarbital therapies (Fig. 1). Both biopsies were normal under light microscopy, but electron microscopic studies showed similar abnormal increased amounts of highly developed smooth endoplasmic reticulum in both biopsies (Fig. 3). Since a biopsy was not obtained while the patient was off medication, it cannot be said that phenobarbital had increased the smooth endoplasmic reticulum over her base-line levels. It can be said, however, that the lack of effect of phenobarbital was not due to a paucity of smooth endoplasmic reticulum. DeLeon et al. [16] have shown that Gunn rats, which are genetically incapable of forming bilirubin glucuronide, also have no lowering of the bilirubin concentration in serum when phenobarbital is given in amounts sufficient to increase the smooth endoplasmic reticulum.

In Figure 4 the labeled bilirubin clearance patterns in plasma obtained in the parents are compared with those observed in the patient in the initial 24-hr period in study 1. Variables of bilirubin metabolism calculated by the plasma curve integral method [22] are shown in Table II and are compared with values determined by Berk et al. [6] for normal individuals. The variables of hepatic function in the father were normal, whereas the mother showed an abnormality in these variables. Her liver function chemistries revealed a normal SGOT, alkaline phosphatase activity, and protein electrophoresis, and she gave no history of acute or chronic liver disease. At the time of her first study she had been on birth control pills for 18 months. Liver specimens from individuals taking oral contraceptives have shown mitochondrial changes and an increase in the amount of smooth endoplasmic reticulum [23]. To make certain that the abnormalities in bilirubin clearance were not due to medication, the birth control pills were stopped, an intrauterine device was inserted, and she was restudied 5 months later. At

Table II. Parameters of bilirubin metabolism in patient and her parents ${ }^{1}$

\begin{tabular}{lccccc}
\hline & Weight, $\mathrm{kg}$ & $\overline{\mathrm{Br}}, \mathrm{mg} / 100 \mathrm{ml}$ & $k_{e}, \min ^{-1}$ & $\mathrm{C}_{\mathrm{Br}}, \mathrm{ml} / \mathrm{min}$ & 4 -hr retention, \% \\
\hline Patient & 7.50 & 16.95 & 0.00015 & 0.1 & 48.9 \\
Father & 66.0 & 0.40 & 0.016 & 64.1 & 2.7 \\
Mother & 65.4 & 0.67 & 0.0073 & 22.4 & 14.1 \\
Normals & & $0.40 \pm 0.09^{2}$ & $0.015 \pm 0.004$ & $47 \pm 10$ & $5.0 \pm 1.9$ \\
\hline
\end{tabular}

$\overline{1} \overline{\mathrm{Br}}$ : mean concentration of plasma unconjugated bilirubin during study; $k_{e}$ : fractional turnover of the plasma unconjugated bilirubin pool per minute; $\mathrm{C}_{\mathrm{B}_{\mathbf{r}}}$ : volume of plasma cleared of bilirubin each minute : 4-hr retention: percentage retention of isotopically labeled bilirubin in plasma at $4 \mathrm{hr}$.

2 Mean \pm so. 


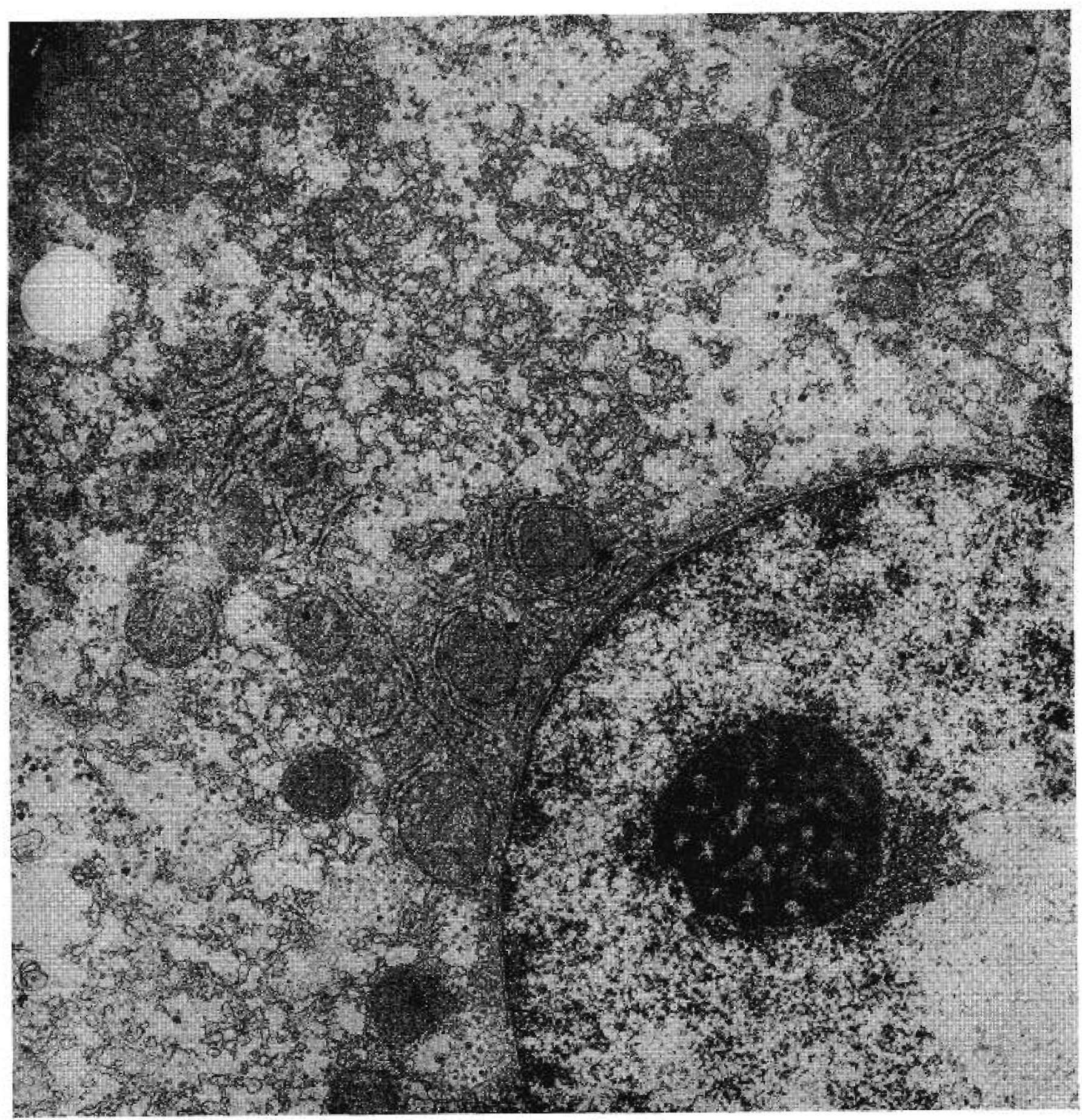

Fig. 3. Electron micrograph of liver biopsy taken while patient was receiving phenobarbital therapy (see Fig. 1). The micrograph shows an abundance of smooth endoplasmic reticulum. $\times 23,000$

this time (second study) her clearance rate of bilirubin was still only $23 \mathrm{ml} / \mathrm{min}$, and $k_{e}$ was $0.0054 \mathrm{~min}^{-1}$, demonstrating that the abnormalities had persisted. These results indicated that she had a defect in he- patic bilirubin clearance, similar to that seen in patients with Gilbert's disease [5].

Although the mother had decreased hepatic bilirubin clearance, her unconjugated bilirubin concentra- 


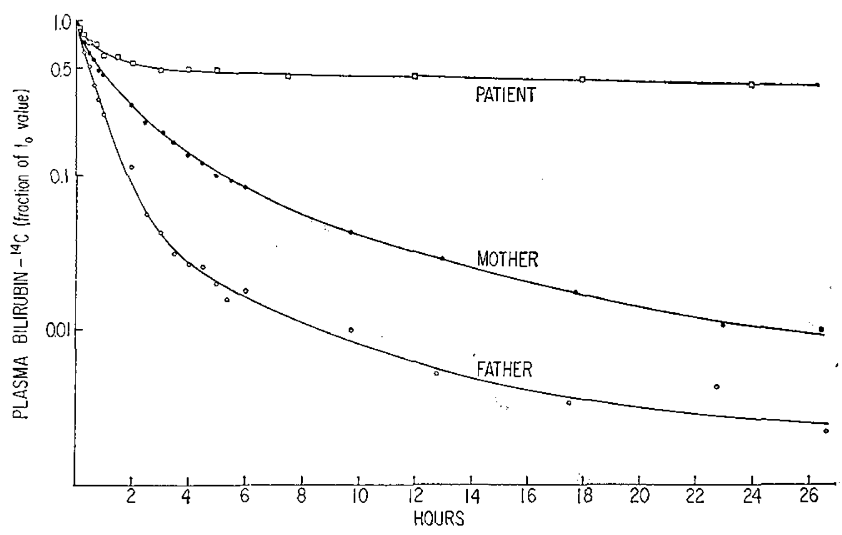

Fig. 4. Plasma bilirubin ${ }^{14} \mathrm{C}$ clearance studies in the patient and her parents. Individual data points are shown as a fraction of the computer extrapolated value at 0 time. The lines represent computer fits to the data.

tion in plasma was only $0.67 \mathrm{mg} / 100 \mathrm{ml}$. We have generally found the unconjugated bilirubin concentration in plasma to be greater than $0.8 \mathrm{mg} / 100 \mathrm{ml}$ when hepatic bilirubin clearance is abnormal (greater than 2 sD below the normal mean), except when a patient has a reduced bilirubin production rate [12]. As the mother did have a modest reduction in the bilirubin productions rate $(3.3 \mathrm{mg} / \mathrm{kg} / 24 \mathrm{hr})$ compared with the mean value seen in normal females $(3.8$ $\mathrm{mg} / \mathrm{kg} / 24 \mathrm{hr}$ ), this may explain why her unconjugated bilirubin concentration was only $0.67 \mathrm{mg} / 100 \mathrm{ml}$.

In study 1 of the patient $26 \%$ of the injected radioactivity was "recovered in the feces over 7 days, while $37 \%$ was recovered in study 2 over the same time period. An additional 24\% was recovered in study 2 over the subsequent 7 days. Crigler and Gold [14] recovered $73 \%$ of the injected radioactivity in the stool over 14 days in their patient. Recovery of radioactivity in the urine of our patient, as well as that reported in the patients of Crigler and Gold [14] and Schmid and Hammaker [25], has ranged from 1 to $7 \%$ of the injected dose for periods of observation up to 14 days. In normal adults recovery of radioactivity averages $92.5 \%$ in the feces and $3.1 \%$ in the urine over 7 days following injection of the isotope [6].

The patient's data were fitted to a number of threepool compartmental models, two of which are illustrated in Figure 2. Since all three pool models are equally compatible with the data, the selection of a particular model cannot be based on these data alone. Previously described considerations suggest that the series arrangement of exchanging pools most closely approximates the physiologic situation [6]. Fractional rates of bilirubin elimination for all series models tested with the patient's data were small in comparison with the intercompartmental transfer rates, so that all series models resulted in essentially the same values for the pool sizes and intercompartmental transfer rates. When the data were fitted to model 1 , the value for $\lambda_{\mathrm{F}, 2}$ was $0.012 \mathrm{hr}^{-1}$. When model 2 was used, $\lambda_{\mathrm{F}, 2}$ had a value of $0.0065 \mathrm{hr}^{-1}$, while $\lambda_{F, 1}$ had a value of $0.0039 \mathrm{hr}^{-1}$. Values for the pool ratios and intercompartmental rate constants based on model 2 are presented in Table III. Results of similar analysis on two previously reported patients are presented for comparison $[14,25]$. In general, the model parameters for the three cases of CNJ studied with radiobilirubin were in good agreement.

In Table IV, the results of studies on the mentholconjugating system are listed. The patient was given

Table IIr. Multicompartmental analysis in congenital nonhemolytic jaundice ${ }^{1}$

\begin{tabular}{lcccc}
\hline & & & $\begin{array}{c}\text { Schmid } \\
\text { and } \\
\text { Hammer's } \\
\text { case }\end{array}$ & $\begin{array}{c}\text { Crigler's } \\
\text { and Gold's } \\
\text { case } \\
\text { (control 1) }\end{array}$ \\
\hline Weight, kg & 7.5 & 20.0 & 7.3 \\
Bilirubin conc, $\mathrm{mg} / 100 \mathrm{ml}$ & 16.95 & 25.56 & 20.0 \\
$\lambda_{21}, \mathrm{hr}^{-1}$ & 0.59 & 0.87 & 0.42 \\
$\lambda_{12}, \mathrm{hr}^{-1}$ & 0.78 & 1.18 & 0.72 \\
$\lambda_{31}, \mathrm{hr}^{-1}$ & & 0.064 & 0.054 & 0.059 \\
$\lambda_{13}, \mathrm{hr}^{-1}$ & 0.114 & 0.072 & 0.156 \\
$\mathrm{M}_{2} \div \mathrm{M}_{1}$ & 0.75 & 0.74 & 0.57 \\
$\mathrm{M}_{3} \div \mathrm{M}_{2}$ & & 0.56 & 0.77 & 0.38 \\
$k_{e}, \mathrm{hr}^{-1}$ & & 0.009 & 0.011 & 0.011 \\
& & & &
\end{tabular}

$1 \lambda_{21}$ : fractional transfer rate of unconjugated bilirubin (FTR) from plasma pool to hepatic pool; $\lambda_{12}$ : FTR from hepatic pool to plasma pool $; \lambda_{31}$ : FTR from plasma pool to extrahepatic extravascular pool; $\lambda_{13}$ : FTR from extrahepatic extravascular pool to plasma pool; $\mathrm{M}_{2} \div \mathrm{M}_{1}$ : ratio of hepatic unconjugated bilirubin pool to plasma pool; $\mathrm{M}_{3} \div \mathrm{M}_{1}$ : ratio of extrahepatic extravascular unconjugated bilirubin pool to plasma pool; $k_{e}$ : fractional turnover of the plasma unconjugated bilirubin pool.

Table IV. Studies on menthol-conjugating system

\begin{tabular}{|c|c|c|c|c|c|c|}
\hline \multirow{2}{*}{\multicolumn{2}{|c|}{$\begin{array}{l}5 \\
3\end{array}$}} & \multirow[b]{2}{*}{ Weight, $\mathrm{kg}$} & \multirow[b]{2}{*}{$\begin{array}{c}\text { Men- } \\
\text { thol } \\
\text { given, } \\
\text { mg/ } \\
\mathrm{kg}\end{array}$} & \multicolumn{2}{|c|}{ Urine } & \multirow[b]{2}{*}{$\Delta \frac{\begin{array}{c}\text { Glucuronide } \\
\text { glucuronic } \\
\text { acid, mmoles }\end{array}}{\begin{array}{c}\text { menthol } \\
\text { given, } \\
\text { mmoles }\end{array}}$} \\
\hline & & & & $\begin{array}{l}\text { Control, } \\
\text { glucu- } \\
\text { ronide } \\
\text { glucu- } \\
\text { ronic } \\
\text { acid } / 5 \mathrm{hr}, \\
\mathrm{mg}\end{array}$ & $\begin{array}{l}\text { After } \\
\text { menthol, } \\
\text { glucu- } \\
\text { ronide } \\
\text { glucu- } \\
\text { ronic } \\
\text { acid } / 5 \mathrm{hr}, \\
\text { mg }\end{array}$ & \\
\hline \multirow{3}{*}{\multicolumn{2}{|c|}{ Patient }} & 8.0 & 15 & 29.6 & 26.9 & 0.00 \\
\hline & & 8.7 & 15 & 25.2 & 23.0 & 0.00 \\
\hline & & 9.0 & 50 & 17.1 & 109.0 & 0.16 \\
\hline \multicolumn{2}{|l|}{ Mother } & 65.4 & 15 & 144.0 & 919.0 & 0.64 \\
\hline \multicolumn{2}{|c|}{ Father } & 66.0 & 15 & 146.8 & 947.9 & 0.65 \\
\hline \multicolumn{2}{|c|}{$\begin{array}{l}\text { Normals }(2-46 \\
\text { yrs) }\end{array}$} & $8-70$ & 15 & - & 一 & $0.53 \pm 0.09$ \\
\hline
\end{tabular}

Mean \pm sD 
phenobarbital during all these studies. On a menthol dose of $15 \mathrm{mg} / \mathrm{kg}$, the patient did not increase her output of glucuronide glucuronic acid normally, whereas her parents did. When a larger dose of menthol was given, her glucuronide output did increase significantly but was still reduced when compared with the amount of menthol given. The testosterone conjugation study showed that more than $90 \%$ of the conjugated testosterone excreted in the urine was as the glucuronide, indicating that this metabolic pathway was probably not deficient [17].

\section{Discussion}

Arias et al. [1] classified patients with congenital nonhemolytic jaundice into two groups. Patients with type I CNJ had more severe hyperbilirubinemia and frequently had kernicterus. The bile of patients with type I CNJ was essentially colorless and contained only traces of unconjugated bilirubin, while the bile from patients with type II CNJ was pigmented and contained bilirubin glucuronide. Transmission of the defect in type I appeared to be autosomal recessive, while it was autosomal dominant in type II. The jaundice in patients with type II decreased markedly on administration of phenobarbital, whereas the drug was ineffective in patients with type $\mathrm{I}$.

As rare as CNJ appears to be in general, the syndrome seems to be even rarer in Negroes. Whitington [29] has reported the only previous case. His case would most closely correspond to an Arias type II, as bile removed from the gallbladder contained $18 \mathrm{mg} /$ $100 \mathrm{ml}$ directly reacting bilirubin by the van den Bergh reaction and $35 \mathrm{mg} / 100 \mathrm{ml}$ total bilirubin. However, three other siblings and both parents were normal, and so the pattern of inheritance was somewhat atypical.

Our patient, on the other hand, clinically resembled the patients described by Arias with type I jaundice. Her duodenal aspirate on two occasions contained no bilirubin, and her bilirubin concentration in plasma did not decrease on phenobarbital therapy. A defect in the menthol tolerance test could not be demonstrated in the parents, however, and no history of consanguinity was obtained through six generations. As Arias et al. [1], as well as Szabó and Ebrey [27], have demonstrated abnormal menthol tolerance and consanguinity in parents of patients with type I CNJ, the mode of inheritance of our patient's defect is uncertain. Labeled bilirubin clearances were carried out on both parents, in a further attempt to define the pattern of inheritance. An abnormality was found in the moth- er's clearance pattern, similar to those seen in patients with Gilbert's syndrome [5], in which hepatic glucuronyl transferase activity is also decreased [11]. This is interesting because unconjugated hyperbilirubinemia has frequently been found in a parent or close relative of a child with congenital nonhemolytic jaundice $[1$, 14, 24].

The value of labeled bilirubin clearances in investigating the effect of drugs on bilirubin metabolism is clearly illustrated in this patient's studies. The bilirubin concentration in plasma decreased significantly during the period while the patient was given diphenylhydantoin for seizure control, but the labeled bilirubin clearance showed that this resulted from decreased bilirubin production and not from more rapid bilirubin elimination.

Multicompartmental analysis of the patient's labeled bilirubin clearance data did not indicate which alternate pathways of bilirubin catabolism were present in CNJ, as several models tested in this patient produced a statistically equivalent fit to the data. However, other aspects of bilirubin metabolism, such as hepatic uptake, could be examined. Although the fractional transfer rate of bilirubin from the plasma pool to the liver was reduced in three patients with CNJ $\left(0.42-0.87 \mathrm{hr}^{-1}\right)$ compared with the rate seen in normal individuals (range $0.9-2.0 \mathrm{hr}^{-1}$ ) [6], this analysis indicates that the capacity for hepatic uptake of bilirubin is very large in these patients $(4.8-12.2 \mathrm{mg} /$ $\mathrm{hr} / \mathrm{kg}$ body wt compared with $0.28 \mathrm{mg} / \mathrm{hr} / \mathrm{kg}$ body wt [6] in normal individuals). The reduced fractiona] transfer rate for hepatic uptake probably reflects saturation either of the hepatic uptake mechanism or of intracellular binding sites, in the face of a serum bilirubin concentration 20-40 times normal.

The studies on other conjugating systems in the patient show that the defect in glucuronide conjugation does not include all compounds. A normal fraction of testosterone conjugated with glucuronic acid was excreted in the urine. Also, while the ability to conjugate menthol was certainly deficient, it was not completely absent. These results add further evidence for a multiplicity of glucuronyl transferase enzymes, whose genetic relations remain to be elucidated.

\section{Summary}

A Negro female with congenital nonhemolytic jaundice (CNJ) was observed over a period of 15 months. During this time the bilirubin concentration in plasma averaged $20.6 \mathrm{mg} / 100 \mathrm{ml}$ and was not lowered by phenobarbital administration. Labeled bilirubin 
clearances in the patient's parents demonstrated a pattern in the mother's clearance similar to that seen in patients with Gilbert's disease, but the father's study was normal. Studies of the patient's ability to glucuronidate other compounds demonstrated a partial deficiency in menthol conjugation, but normal amounts of testosterone were excreted conjugated with glucuronic acid.

\section{References and Notes}

1. Arias, I. M., Gartner, L. M., Comen, M., Ben Ezzer, J., and LeVI, A. J.: Chronic nonhemolytic unconjugated hyperbilirubinemia with glucuronyl transferase deficiency. Amer. J. Med., 47: 395 (1969).

2. Axelrod, J., Schmid, R., and Hammaker, L. A.: A biochemical lesion in congenital non-obstructive non-hemolytic jaundice. Nature, 180: 1426 (1957).

3. Barrett, P. V. D., Berk, P. D., Menken, M., AND Berlin, N. I.: Bilirubin turnover studies in normal and pathologic states using bilirubin-14 C. Ann. Intern. Med., 68: 355 (1968).

4. BarretT, P. V. D., Mullins, F. X., AND Berlin, N. I.: Studies on the biosynthetic production of bilirubin ${ }^{11} \mathrm{C}$; an improved method utilizing $\delta$-aminolevulinic acid- $-4{ }^{14} \mathrm{C}$ in dogs. J. Lab. Clin. Med., 68: 905 (1966).

5. BERK, P. D., Bloomer, J. R., Howe, R. B., AND Berlin, N. I.: Constitutional hepatic dynsfunction (Gilbert's syndrome): A new definition based on kinetic studies with unconjugated bilirubin. Amer. J. Med. (in press).

6. Berk, P. D., Howe, R. B., Bloomer, J. R., AND Berlin, N. I.: Studies of bilirubin kinetics in normal adults. J. Clin. Invest., 48: 2176 (1969).

7. BERMAN, M.: The formulation and testing of models. Ann. N. Y. Acad. Sci., 108: 182 (1963).

8. BERMAN, M., AND SCHOENFIELD, R.: Invariants in experimental data on linear kinetics and the formulation of models. J. Appl. Physics, 27: 1361 (1956).

9. Berman, M., Shahn, E.,' And Werss, M. F.: The routine fitting of kinetic data to models: A mathematical formalism for digital computers. Biophys. J., 2: 275 (1962).

10. Berman, M., And Weiss, M. F.: Users' Manual for SAAM. Public Health Service Publication no. 1703. (Department of Health, Education, and Welfare, U. S. Government Printing Office, Washington, D. C., 1967).

11. BLACK, M., AND Buclung, B. H.: Hepatic bilirubin UDPglucuronyl transferase activity in liver disease and Gilbert's syndrome. New Engl. J. Med., 280: 1266 (1969).

12. Bloomer, J. R., Berk, P. D., Howe, P. B., AND BerLin, N. I.: Interpretation of plasma bilirubin levels based on studies with radiobilirubin. J. Amer. Med. Ass., in press.

13. Conney, A. H.: Pharmacological implications of microsomal enzyme induction. Pharmacol. Rev., 19: 317 (1967).

14. Crigler, J. F., JR., and Gold, N. I.: Effect of sodium phenobarbital on metabolism in an infant with congenital, nonhemolytic unconjugated hyperbilirubinemia, and kernicterus. J. Clin. Invest., 48 : 42 (1969).
15. Crigler, J. F., JR., ANd NaJjar, V. A.: Congenital familial nonhemolytic jaundice with kernicterus. Pediatrics, 10: 169 (1952).

16. Deleon, A., Gartner, L. A., and Arias, I. M.: The effect of phenobarbital on hyperbilirubinemia in glucuronyl transferase deficient rats. J. Lab. Clin. Med., 70: 273 (1967).

17. Dulmanis, A., Coghlan, J. P., Wintour, M., and Hudson, B.: The estimation of testosterone in biological fluids: II. Testosterone in urine. Aust. J. Exp. Biol. Med. Sci., 42: 385 (1964).

18. Fishman, W. H., and Green, S.: Microanalysis of glucuronide glucuronic acid as applied to $\beta$-glucuronidase and glucuronic acid studies. J. Biol. Chem., 215: 527 (1955).

19. Hawkins, W. B., and Whipple, G. H.: The life cycle of the red blood cell in the dog. Amer. J. Physiol., 122: 418 (1938).

20. Howe, R. B., Berk, P. D., Bloomer, J. R., and Berlin, N. I.: Preparation and properties of specifically-labeled radiochemically stable ${ }^{3} \mathrm{H}$-bilirubin. J. Lab. Clin. Med., 75: 499 (1970).

21. Korenman, S. G., Wilson, H., and Lipsert, M. B.: Testosterone production rates in normal adults. J. Clin. Invest., 42: 1753 (1963).

22. Nosslin, B.: Mathematical appendices. In: S. B. Andersen: Metabolism of Human Gamma Globulin (Blackwell, Oxford, 1964).

23. Perez, V., Gorodisch, S., DeMartine, J., Nicholson, R., ANd DiPAOLA, G.: Oral contraceptives: Long-term use produces fine structural changes in liver mitochondria. Science, 165: 805 (1969).

24. Schmid, R.: Hyperbilirubinemia. In: J. B. Stanbury, J. B. Wyngarden, and D. S. Frederickson: The Metabolic Basis of Inherited Disease, p. 871 (McGraw-Hill, New York, 1966).

25. Schmid, R., and Hammaker, L.: Metabolism and disposition of $\mathrm{C}^{14}$-bilirubin in congenital non-hemolytic jaundice. $\mathrm{J}$. Clin. Invest., 42: 1720 (1963).

26. Sterling, K.: The turnover rate of serum albumin in man as measured by ${ }^{131} \mathrm{I}$ tagged albumin. J. Clin. Invest., 30: 1228 (1951).

27. Szabó, L., AND EBrex, P.: Studies on the inheritance of Crigler-Najjar's syndrome by the menthol test. Acta Paediat. Acad. Sci. Hung., 4: 153 (1963).

28. Weber, A. P., AND Schalm, L.: Quantitative separation and determination of bilirubin and conjugated bilirubin in human serum. Clin. Chim. Acta, 7: 805 (1962).

29. Whitrngton, G. L.: Congenital nonhemolytic icterus with damage to the central nervous system. Pediatrics, 7: 437 $(1960)$.

30. Valium, Roche, Nutley, N. J.

31. Dilantin, Parke Davis, Detroit, Mich.

32. Univac 1108, Sperry-Rand, St. Paul, Minn.

33. We thank Drs. Rudi Schmid and John Crigler for supplying isotopic bilirubin clearance data on patients with CNJ; Dr. C. Wayne Bardin of the National Cancer Institute, National Institutes of Health, for analysis of testosterone conjugation in the patient; and Dr. Philip Grimley of the Clinical Pathology Department, National Institutes of Health, for reading electron micrographs of the patient's liver biopsy.

34. Address requests for reprints to: Joseph R. Bloomer, M.D., National Cancer Institute, Bldg. 10, Room 4N117, National Institutes of Health, Bethesda, Md. 20014 (USA).

35. Accepted for publication September 11, 1970. 